Audiology

Neurotology
Audiol Neurotol 2008;13:370-378

DOI: $\underline{10.1159 / 000148200}$
Received: October 9, 2007

Accepted after revision: April 9, 2008

Published online: July 29, 2008

\title{
Using Early Language Outcomes to Predict Later Language Ability in Children with Cochlear Implants
}

\author{
Marcia J. Hay-McCutcheon ${ }^{a}$ Karen ller Kirk ${ }^{b, d}$ Shirley C. Henning ${ }^{b}$ Sujuan Gao ${ }^{c}$ \\ Rong Qic

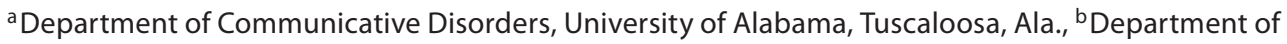 \\ Otolaryngology, Head and Neck Surgery, and ' Division of Biostatistics, Indiana University School of Medicine, \\ Indianapolis, Ind., and d Department of Speech, Language and Hearing Sciences, Purdue University, \\ West Lafayette, Ind., USA
}

\section{Key Words}

Cochlear implants $\cdot$ Receptive language $\cdot$ Expressive language $\cdot$ Speech perception

\begin{abstract}
The increased access to sound that cochlear implants have provided to profoundly deaf children has allowed them to develop English speech and language skills more successfully than using hearing aids alone. The purpose of this study was to determine how well early postimplant language skills were able to predict later language ability. Thirty children who received a cochlear implant between the years 1991 and 2000 were study participants. The Reynell Developmental Language Scales (RDLS) and the Clinical Evaluation of Language Fundamentals (CELF) were used as language measures. Results revealed that early receptive language skills as measured using the RDLS were good predictors of later core language ability assessed by the CELF. Alternatively, early expressive language skills were not found to be good predictors of later language performance. The age at which a child received an implant was found to have a significant impact on the early language measures, but not the later language measure, or on the ability of the RDLS to predict performance on the CELF measure.

Copyright $\odot 2008$ S. Karger AG, Basel
\end{abstract}

\section{Introduction}

The development of speech perception skills after cochlear implantation in profoundly deaf children has been well documented [Blamey et al., 2001; Geers et al., 2003; Kirk et al., 2000]. Evidence has suggested that children with cochlear implants on average are able to achieve between 40 and $60 \%$ results on open-set tests of word recognition [Blamey et al., 2001; Geers et al., 2003]. In addition, greater improvements in speech perception are generally observed with increased durations of implant use and with earlier ages of implantation [Kirk et al., 2002; Miyamoto et al., 2000]. Previous research has also suggested that children can use the increased access to sound provided via the cochlear implant to develop their expressive and receptive language skills across time [Connor et al., 2006; Dettman et al., 2007; Kirk et al., 2002; Svirsky et al., 2004; Tomblin et al., 1999]. Although profoundly deaf children display a gap in their language skills compared to their normal-hearing age-matched peers, once they receive a cochlear implant they can start

Portions of these data were presented at the 9th International Conference on Cochlear Implants and Related Sciences, Vienna, Austria.

\section{KARGER}

\section{๑) 2008 S. Karger AG, Basel}

Fax +41613061234 E-Mail karger@karger.ch www.karger.com www.karger.com/aud
Marcia J. Hay-McCutcheon, $\mathrm{PhD}$

University of Alabama

Department of Communicative Disorders

Box 870242, Tuscaloosa, AL 35487 (USA)

Tel. +1 205348 4572, Fax +1 205348 1845, E-Mail mhaymccu@as.ua.edu 
developing near-normal rates of language growth [Kirk et al., 2002; Svirsky et al., 2004].

A number of studies have suggested that age of implantation and the duration of implant use are significant factors to help promote the development of language skills. Kirk et al. [2002] reported that children who received a cochlear implant prior to the age of 3 years performed better on the receptive and expressive subtests of the Reynell Developmental Language Scales (RDLS) across time than children who were implanted at a later age. Svirsky et al. [2004] used developmental trajectory analyses to compare the language growth of children implanted in the second, third or fourth year of life. This study demonstrated that children implanted between the ages of 16-24 months performed more similarly to their normal-hearing age-matched peers on the expressive subtest of the RDLS with increased implant use than did children implanted between the ages of 25-36 months. Also, Tomblin et al. [2005] using cross-sectional and growth curve analyses revealed that age of implantation accounted for $14.6 \%$ of the variance observed in the expressive language scores in a group of 29 pediatric cochlear implant recipients. The results of this study showed that early implantation resulted in higher expressive language abilities. Connor et al. [2006] demonstrated that after approximately 2 years of implant use, children implanted before 30 months of age who used oral communication had mean vocabulary skills that were age appropriate. Children who were implanted when they were older than 2.5 years had below-average vocabulary skills. Nicholas and Geers [2006] conducted a cross-sectional examination of language development in a group of children who were implanted between the ages of 12 and 38 months, and tested them when they were approximately 3 years 6 months old. Their findings indicated that, after approximately 1 year of cochlear implant use, language skills began to increase significantly. Additionally, continued gains in language skills were observed with each additional month of implant use. All of these studies have provided overwhelming evidence that early implantation leads to improved language skills. Interestingly, however, studies conducted by Geers et al. [2003] and Geers [2004] assessing linguistic skills of 8- and 9-year-old cochlear implant recipients revealed that implantation at 2 or 3 years of age did not provide a significantly greater benefit for language skill level in comparison to children who were implanted at 4 or 5 years of age.

In the studies that have assessed the importance of early implantation, the performance of the children is typically not tracked into later childhood or adolescence.
In order to determine the benefits of early implantation for later language competence it will be necessary to evaluate children as they mature. It is known that early implantation is beneficial for early language competence, but is this factor also important for later linguistic competence? According to Scott [1988] and Scott and Stokes [1995], school-aged children and adolescents are required to understand and use more complex phrase and clause structures for communication purposes, such as adverbials and relatives. Does the age at which a profoundly deaf child receives an implant have long-lasting consequences for language abilities?

Currently, studies that have assessed the linguistic skills of school-aged cochlear implant recipients suggest that they perform better than their profoundly deaf agedmatched peers, and additionally, that some perform at levels comparable to their normal-hearing peers. Tomblin et al. [1999] examined the expressive and receptive language skills of a group of 29 pediatric cochlear implant recipients (mean age $=10$ years old) who relied on both sign and speech for communication purposes. This study revealed a mean percentile rank of 92.2 on the Rhode Island Test of Language Structure for children with cochlear implants. The Rhode Island Test of Language Structure has normative data based on nonimplanted deaf children. The results demonstrated that many of the pediatric cochlear implant recipients were at or approached ceiling levels of performance. In addition, it was found that more than half of the children who used cochlear implants had significantly higher expressive language scores than a comparison group of 29 agematched peers who were profoundly deaf and used hearing aids.

More recently, studies have demonstrated that some school-aged children with cochlear implants are capable of achieving mastery of reading and language skills as assessed using tests created for normal-hearing children. Spencer et al. [2003, 2004] administered subtests of the Woodcock Reading Mastery Test to groups of pediatric cochlear implant recipients and revealed that, although their mean performance was below that of the normalhearing aged-matched peer group, a small group of children were capable of performing at average levels obtained by normal-hearing children. Additionally, Geers et al. [2003] demonstrated that approximately half of the 8- and 9-year-old cochlear implant recipients examined were able to perform comparably to their normal-hearing peers on language tests that assessed verbal reasoning and narrative ability, utterance length, and lexical diversity. In all of these studies, however, the early language 
skills of the children were not reported, and, therefore, it is not certain if early language skills were related to or predicted later language abilities.

There is evidence, however, from children with normal hearing and children with cochlear implants that early specific language skills can be predictive of later performance in other language skills. For example, Stallings et al. [2002] examined a group of profoundly deaf children who used cochlear implants and discovered that data from the Words and Gestures and Words and Sentences subtests of the MacArthur Communicative Development Inventories, a parental questionnaire for infants and toddlers, were highly correlated with and predicted performance on both the expressive and receptive scales of the RDLS, a normative language measure used with children aged 1-7 years old. Also, evidence from studies conducted with children who have normal hearing revealed that a young child's mean length of utterance is a valid indicator of general language development across time and can predict the rate of verb tense acquisition [Rice et al., 1998, 2006]. Nippold et al. [2005] have also provided evidence that the length of a child's terminal unit (i.e., the length of an attached or embedded clause within a main clause) and his or her use of relative clauses were highly correlated with conversational and expository discourse skills in adolescence and adulthood.

The findings reported in the above studies assessing preschool and school-aged language abilities suggest that with implantation the rates of language growth in profoundly deaf children significantly increase compared to their rate of growth prior to implantation, and that some school-aged children have language skills similar to their normal-hearing peers. Also, there is some evidence suggesting that the understanding of words and sentences in the toddler years can predict receptive and expressive language skills later in childhood for children who use cochlear implants. In order to provide effective and appropriate intervention programs for pediatric cochlear implant recipients, determining the relationship between preschool and school-aged language skills would be beneficial for early intervention programs to help address specific areas of need.

The benefit of early cochlear implantation for language development that has been demonstrated in the preschool population has been attributed to the increased access to sound during a sensitive period where experience is crucial for development [Tomblin et al., 2007]. In this study, we explore whether or not this early increased access to sound via a cochlear implant can be used to help profoundly deaf children sustain the development of re-

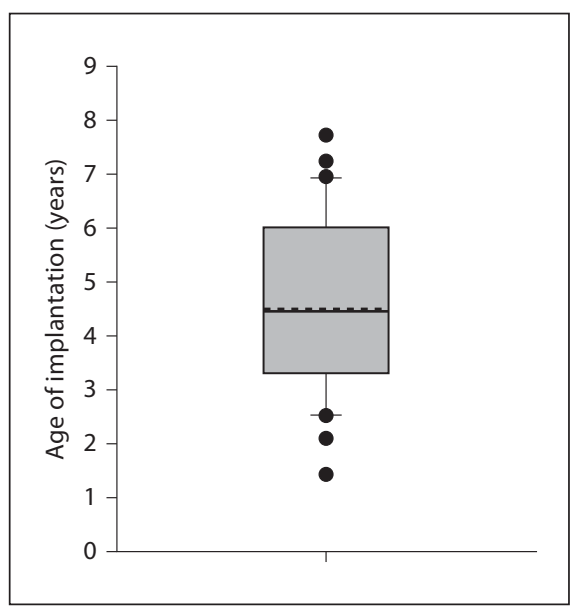

Fig. 1. A box plot showing the distribution of the ages at which the 30 children enrolled in this study received their implant. The age of implantation in years is shown on the $y$-axis.

ceptive and expressive language skills into the pre-teen and teenage years. The rapid growth of speech perception skills with implantation before 24 months of age has been associated with near-normal rates of language growth [Svirsky et al., 2004]. The objectives of this current study, therefore, were to determine if early postimplant language skills can be a predictor of later language ability, and to determine the impact that age at implantation has on language skills in the later childhood years.

\section{Methods}

\section{Study Participants}

A total of 30 congenitally deaf children who used cochlear implants were included in this longitudinal study. They were implanted between the years 1991 and 2000, and the mean age of implantation was 4.48 years $( \pm 1.61 \mathrm{SD}$, range $1.4-7.7)$. The box plot in figure 1 displays the distributions for the ages at which the children were implanted. In the box, the solid horizontal line represents the median and the dashed line represents the mean age of implantation. As observed in the figure, the mean (4.48 years) and median (4.42 years) points are very similar. The mode of communication was assessed via parental report. Twenty families of the children reported that their child used oral communication in both the school and home environment. Ten families reported that their child used a combination of sign plus oral communication (i.e., total communication) in the home and school environment. All of the families exclusively used American English. Twenty-two children used the Spectral Peak speech encoding strategy, 3 children used the Advanced Combination Encoder strategy, 4 children used the Continuous Interleaved Sampling strategy, and 1 child used the Simultaneous Analog Stimulation processing strategy. 


\section{Procedures and Testing Materials}

A battery of language and speech perception tests were administered to the children in our longitudinal study on a semi-annual basis (i.e., every 6 months) for a period of up to 3 years or until they were 6 years old. After this period, the children were tested on an annual basis until they reached 9 years of age. Once they reached the age of 9 , they were tested every 3 years until they were 18 years old. There were instances, however, when children were not able to return to our center every 6 months, or were not able to complete all of the measures administered to them at one interval due to time constraints on the family or due to the child's attention span. For purposes of this study, therefore, data points were collapsed over a 1-year period. If only one data point was available in a 12-month period that result was used for analyses. Alternatively, if two data points were obtained over a 12-month period, the higher score obtained over this time frame was used for analyses. Typically, the latest test score within the 12-month period was the higher test score. This higher score was used in order to represent the language and speech perception development that took place within the time interval.

The language tests that are administered to the children vary as a function of their chronological age and their language abilities. For our research studies, the RDLS were administered to children who were between 1 and 7 years old (more detail is provided below). Because this test is not valid for children who are over the age of 7 years, it is necessary to administer other age-appropriate tests to older children. The language tests for older children evaluate the child's knowledge of more complex language structures, and as a result, are more challenging for the children. One of the tests used in our laboratory was the Clinical Evaluation of Language Fundamentals (CELF); it is appropriate for children who range in age from 5 to 21 years (more detail is provided below). We used language measures that have been standardized on normal-hearing children in order to assess how profoundly deaf children with cochlear implants compare to their age-matched normal-hearing peers. In order to be included in this study, the children had to have received at least one administration of the CELF test when they were 9 years of age or older. Additionally, all of the children who received the CELF test also had at least two testing intervals when they were administered the RDLS. Two measures of the RDLS were necessary in order to obtain slope measurements for data analysis. Both of the language tests were administered to the children in their preferred mode of communication (i.e., oral or total communication), and the child's response was given in his or her preferred mode of communication. For the children who were administered the test using total communication, some of the manual signs may have provided iconic clues that helped with understanding receptive vocabulary items (e.g. 'brush'). However, because both language tests assessed conceptual reasoning and the ability to use language for expressing thoughts and ideas rather than lexical knowledge, the advantage that manual signs provided to these children, as compared to the children who used oral communication and did not receive iconic clues, was most likely minimal.

\section{Reynell Developmental Language Scales}

The RDLS consist of both a verbal comprehension scale and an expressive language scale. They have been standardized on a group of 1318 normal-hearing children from England ranging in age from 1 to 7 years old [Reynell and Huntley, 1985]. At the be- ginning level of the receptive language subtest, the verbal comprehension scale evaluates the child's ability to distinguish among a few word sounds, and at the most advanced level this scale evaluates the child's ability to use vocabulary for conceptual reasoning. The expressive language scale evaluates the use of vocal language structure, the use of vocabulary to name and describe word meanings, and the use of language to express ideas. This test, although not standardized for the hearing-impaired population, has been used extensively with deaf children [DesJardin and Eisenberg, 2007; Johnson et al., 2008; Kirk et al., 2002; Robbins et al., 1997; Svirsky et al., 2004].

Scoring. The table provided in the examiner's manual was used to convert the raw scores obtained on the receptive and expressive portions of this language test to age-equivalent language scores. The age-equivalent language scores are based on the typical language levels for children with normal hearing.

\section{Clinical Evaluation of Language Fundamentals}

This language assessment is intended to identify and diagnose language and communication disorders in normal-hearing children ranging in age from 5 to 21 years old. The general language areas that are evaluated in the $3 \mathrm{rd}$ and 4 th version of this test are word meanings (semantics), word and sentence structure (morphology and syntax), and recall and retrieval of spoken language (memory) [Semel et al., 1996, 2003]. Within these language areas, both receptive (e.g. following directions and vocabulary knowledge) and expressive (e.g. recalling sentences and formulating sentences) subtests are administered. Additionally, the 4th edition of the CELF assesses the child's use of rules for responding to and conveying messages in oral language (i.e., pragmatics) [Semel et al., 2003]. The children who were evaluated as part of this study received either the 3 rd or 4 th edition of this test. Reliability studies have indicated excellent correlation between the scores obtained on both editions [Semel et al., 2003]. The subtests that were used to evaluate the language skills of the children in this study who were between 9 and 12 years of age were concepts and following directions, recalling sentences, formulating sentences, and receptive and expressive word classes (i.e., understanding and expressing relationships between words). For adolescents over the age of 13 years old, the subtests recalling sentences, formulating sentences, expressive and receptive word classes, and word definitions were administered.

Scoring. Using the normative data provided in the test manual, each raw score from the above-mentioned subtests was used to generate an overall core language percentile rank. Specifically, scaled scores from each of the subtests were obtained using the raw scores and the normative data provided in the examiner's manual. The scaled scores from each subtest were summed to produce one overall scaled score which was converted to a core language percentile rank score, again using the normative data provided in the manual. Individual percentile rank scores indicate the percentage of scores in the norm group who scored below this value. The 50 th percentile is the point at which $50 \%$ of the scores fall above and below this value and is referred to as the median.

\section{Data Analysis}

Mixed-effect models were first used to determine whether age at implantation and communication mode were associated with RDLS language measures. Repeated RDLS scores were used as the dependent variable and age at implantation and communication 


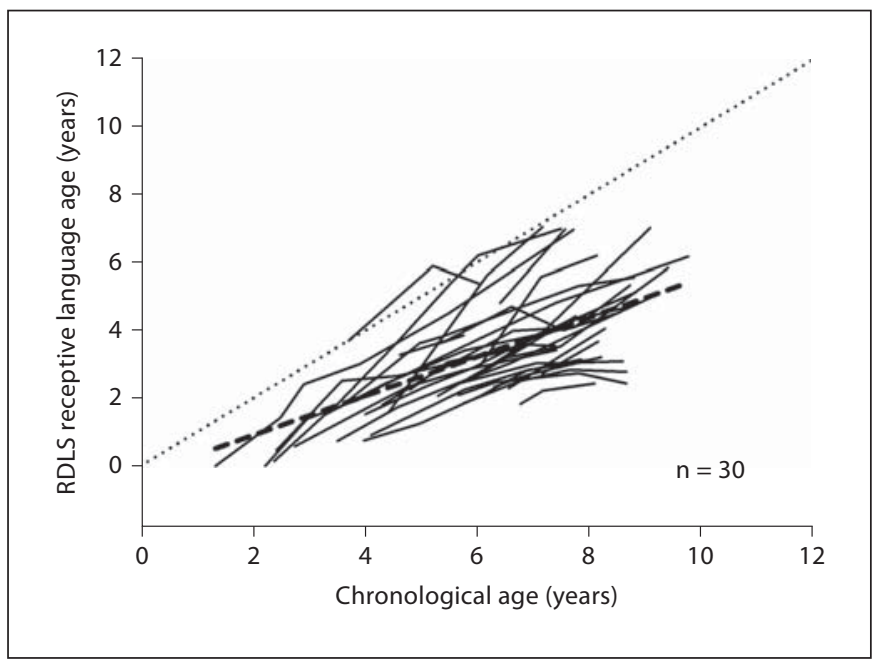

Fig. 2. The RDLS receptive language age. The chronological age is shown on the abscissa and the receptive language age (in years) is shown on the ordinate. Each solid line represents the data for 1 child. The dotted line represents the normative data or the points at which the chronological ages are equivalent to the language ages. The dashed line represents the best-fit linear regression line.

mode were used as independent variables while controlling for potential correlation induced by repeated measures from the same subject. In order to determine if the development of language skills as assessed using the RDLS was associated with later performance on the CELF language test, a two-stage repeatedmeasures mixed model was used. At the first stage, regression models were conducted with equivalent language age scores of the RDLS language measures as dependent variables and age at testing as the independent variable. Slope estimates obtained from these regression models represent annual changes in the RDLS scores for each individual. At the second stage, mixed-effect models were used with repeated CELF language measures as the dependent variable, slope estimates from the first-stage regression models were used as predictor variables and communication mode used by the child and age at implantation as covariates. The analyses were conducted using the SAS for Windows (version 9.1) statistical analysis program.

\section{Results}

Figure 2 shows the individual performance results for the RDLS receptive language task. The chronological age is shown on the abscissa and the receptive equivalent language age on the ordinate. The average performance for normal-hearing children (i.e., language age equal to chronological age) is denoted using the dotted line. Each solid line in the figure represents the data for 1 child. The dashed line is the linear regression model fit to the

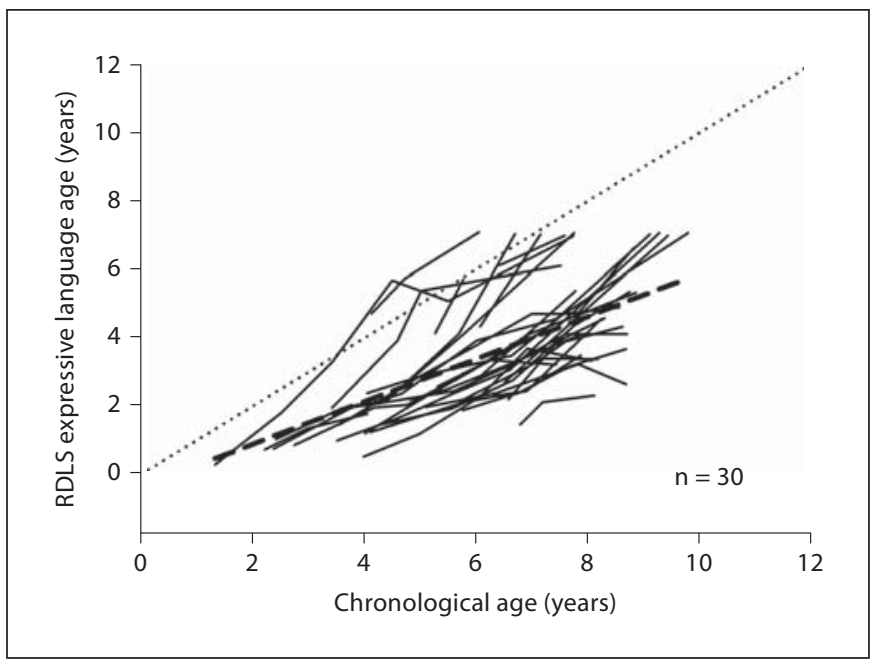

Fig. 3. The expressive language ages obtained from the RDLS test. The expressive language ages are shown as a function of age at test. Each solid line represents the data for an individual child, the dotted line represents the normative data, and the dashed line is the best-fit linear regression line.

data. In the figure, it can be observed that the receptive language ages for this group of children vary widely as some children performed at or near the average age for normal-hearing children and others were far below the average performance. Although the slope of the linear regression line was significantly positive $\left(t_{1,69}=16.89\right.$, $\mathrm{p}<0.0001)$ - implying that the average receptive language age was increasing as the children aged - the gap between the average performance for normal-hearing children and the overall mean performance on this receptive language task increased with chronological age. This finding suggests that the receptive language skills of the children in this study were not keeping pace with the development of their normal-hearing peers. The mean language age of the children obtained at the final testing session was 7.99 years ( $\pm 1.15 \mathrm{SD})$. Analyses using mixedeffect models indicated that the mode of communication used by the children did not account for the observed differences in performance but the age at implantation had a significant impact on the outcomes $\left(\mathrm{t}_{1,116}=-2.56, \mathrm{p}=\right.$ $0.01)$. For every year younger a child received an implant the receptive language age increased by 0.32 points.

The expressive language results from the RDLS test are presented in figure 3 . The RDLS expressive language age is shown as a function of chronological age. As in figure 2 , the dotted line represents the average expressive language performance for a normal-hearing child and each 


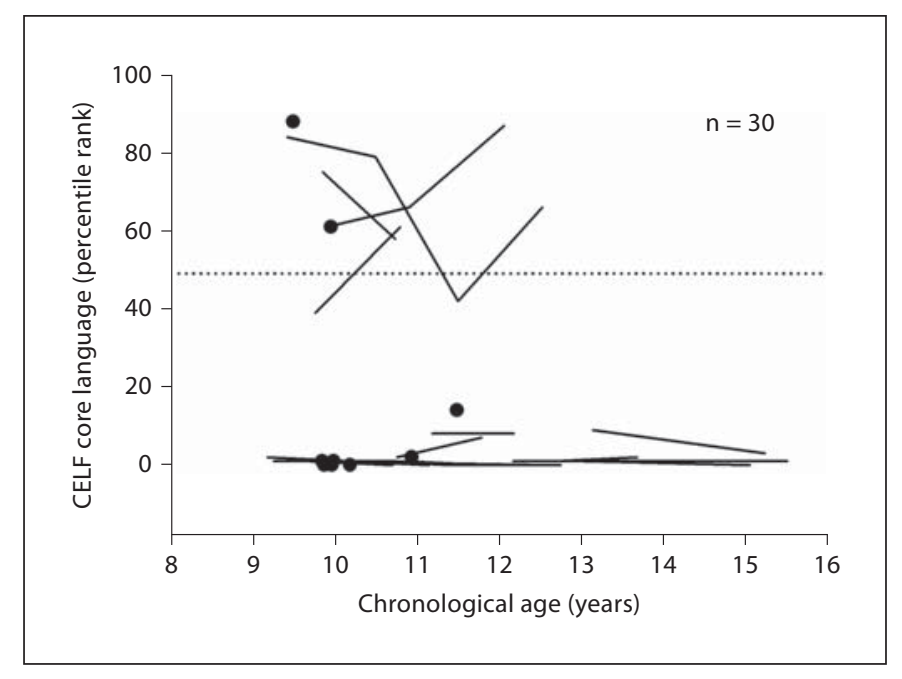

Fig. 4. The CELF core language percentile rank scores. The abscissa shows the age at test in years and the ordinate displays the CELF scores. Each solid line represents the results across time for 1 child, and, alternatively, for those children who only had one result, each symbol represents their data point. The dotted line represents the scores obtained at the 50th percentile rank.

solid line represents the data collected over time for an individual child. The dashed line is the best-fit linear regression line. The slope of the regression line was significantly positive $\left(t_{1,67}=17.99, p<0.0001\right)$. Similar to the results from the receptive language data, some children performed at or near the average performance for normalhearing children and others performed well below the average. In addition, the gap between the linear regression line and the performance for normal-hearing children (i.e., the dotted line) increased as the children aged. This finding suggests that on average, 1 year of language age development was not occurring over a 1-year period. The mean language age obtained at the final testing session was 7.96 years $( \pm 1.17 \mathrm{SD})$. The age of implantation was a significant factor that affected these outcomes $\left(t_{1,116}=\right.$ $-2.69, \mathrm{p}=0.008)$. Analyses using mixed-effect models indicated that for every year younger at implantation the expressive language age increased by 0.40 points. The mode of communication used by the children was not found to significantly affect these outcomes.

The CELF core language percentile rank scores are displayed in figure 4 . The abscissa shows the chronological age at test in years and the ordinate displays the CELF scores. Each line represents the results across time for 1 child, and alternatively, for those children who only had one result, each symbol represents their datum point. The median or 50th percentile rank for the normative group is indicated using the dotted line. Although the majority of the results were from children between the ages of 9 and 13 years old, there were some results for children who were 17 years of age. In general, the majority of the CELF percentile rank scores fell well below the 50th percentile. In fact, the majority of the scores were close to floor performance with a percentile rank of 0 . Neither the age of implantation nor the mode of communication was a significant factor in the outcomes of this language measure.

The purpose of this study was to determine if the language scores that the children obtained in their preschool and early school years could be used to predict later language performance. In order to do this, the slopes of the language age data from the RDLS were used to perform the mixed-model analyses as discussed in the Method section. For the RDLS receptive language scores, the repeated-measures analyses suggested that the slopes were significant predictors of the performance on the CELF language measure $\left(t_{1,55}=3.55, p=0.0008\right)$. The results suggested that for every 0.1 increase in the slope of the RDLS receptive language functions, the subsequent CELF percentile rank score improved by an estimate of 3.06 points. The age of implantation and the communication mode were not significant factors in these outcomes. Alternatively, the slopes of the RDLS expressive language quotient scores were not significant predictors of later core language performance on the CELF test.

\section{Discussion}

The findings from this study suggest that receptive, as opposed to expressive, language skills that cochlear-implanted children develop when they are young can be used to predict later language abilities. Additionally, our data suggest that the age of implantation had a significant impact on early receptive and expressive language skills, but this factor was not important for later language performance. For profoundly deaf children, the development of expressive language skills has historically lagged behind the development of receptive language abilities [Kirk et al., 2002; Miyamoto et al., 1986]. It is more challenging for children to use language for expression purposes than to understand the communication messages of others. The fact that expressive language cannot be used to predict later language performance might suggest, therefore, that the development of these skills is much slower and/or variable compared to the development of receptive language skills. 
Early Language Skills and Later Linguistic Ability

Tomblin et al. [1999] also demonstrated that early skills do not necessarily predict later performance when assessing expressive language skills. Specifically, after analyzing expressive language samples for the use of noun and verb phrases, questions, negations, and simple and complex sentence forms, the performance after 1 year of implant use did not predict the performance after 4 years of use. However, the performance after 2 years of implant use was highly correlated with the performance after 3 years of use, and the performance after 3 years of use was highly correlated with the performance after 4 years of use. It was suggested that the significant correlations in performance from one testing interval to the next indicated that language achievement was stable in successive years and provided good test-retest reliability for the language measure. Although the results from the current study spanned a longer period of time than those from Tomblin et al. [1999], both studies suggest that early expressive language ability cannot be used to predict later performance.

There are potential clinical implications for these outcomes. Specifically, the results from this study suggest that, if early receptive language development can be used to predict later language performance, early habilitation programs should continue to emphasize the development of these skills. Historically, the development of receptive language skills in deaf children has been given much attention [Moeller and McConkey, 1984; Streng et al., 1978], and the findings from this study further emphasize the importance of these skills for overall linguistic competence. The results from this study might also suggest that expressive language skills are not developing in tandem with receptive language skills. Habilitation sessions, therefore, should place particular emphasis on the development of expressive language so that profoundly deaf children who use cochlear implants will be able to use their receptive language knowledge to successfully express themselves. Further work, however, should verify the findings from this study and determine the importance of language growth during successive years to help promote language growth across the years.

\section{Age of Implantation and Language Ability}

The benefits of early implantation for language development have been well documented [Connor et al., 2006; Dettman et al., 2007; Kirk et al., 2002; Svirsky et al., 2004]. In agreement with these research findings, the data from our study suggest that early implantation promotes the development of early receptive and expressive language skills. Our findings, however, also suggest that the age at which a child receives a cochlear implant does not have a significant impact on the receptive and expressive language abilities of these children when they are 9 or 10 years of age or older. Geers [2004] and Geers et al. [2003] also demonstrated that early implantation might not have an impact on later linguistic ability. In these studies, children who were implanted at 2 or 3 years of age did not demonstrate increased linguistic ability in comparison to children who were implanted at 4 or 5 years of age when they were all tested at 8 or 9 years of age. To explain these findings, the investigators suggested, among other factors, that implantation at 2 years of age or older might not be young enough to show the advantage of early auditory input. Perhaps, they argued, implantation under the age of 2 years would be more effective for sustained linguistic development. In our study, the mean age of implantation was 4.48 years with a range of $1.4-7.7$ years. It is possible, therefore, that the beneficial effects of earlier implantation were not observed with performance on the later school-aged language test because the children were not able to take full advantage of very early auditory input. Perhaps the sensitive period for language development was not fully exploited due to the limited auditory access during this time.

Our findings might also be due to the lack of variability in the observed percentile rank CELF scores. If the performance had been more evenly dispersed across the range of possible scores, the age of implantation effects might have emerged. Future work should assess the children who performed poorly on the CELF language test using more sensitive language measures to appropriately describe their language abilities. With more variability in the data it might be possible to more effectively predict later language performance using early language ability.

Finally, it is also possible that other unknown variables might be involved in the outcomes observed in this study. For example, evidence has suggested that cognitive factors, such as short-term memory processing, have an impact on linguistic ability [Dawson et al., 2002; Pisoni, 2000; Willstedt-Svensson et al., 2004], and, at later ages, it might be possible that these factors have more of an impact on language ability than the age at which children receive an implant. In order to promote the development of language throughout childhood and adolescence it will be necessary to determine the reasons for the below-average performance on later language measures observed in this study. 


\section{Communication Mode and Linguistic Ability}

In this study, communication mode was not shown to have an effect on the overall language outcomes. Previous studies have also examined the impact that the mode of communication has on language skill ability and demonstrated inconsistent findings. No significant differences between the receptive and expressive language skill abilities of children who use oral or total communication have been demonstrated [Connor et al., 2000; Robbins et al., 1999]. Kirk et al. [2002] found no differences in the rate of growth of receptive language skills between children who used oral or total communication, but did reveal slower rates of expressive language growth for children who used total communication compared to oral communication. Geers et al. [2003] revealed no significant differences between children who used oral or total communication for verbal reasoning or language comprehension but did find that children who used oral communication were more proficient in narrative abilities. However, when examining a group of educational variables that made an independent contribution to language development, communication mode was an important factor children with more of an oral emphasis to their educational settings had better language skills than children who used a combination of sign and speaking.

\section{Conclusions}

The results from this study suggest that the performance on receptive language tasks after cochlear implantation can be a predictor of later performance on more complex language measures. Alternatively, early expressive language skills did not predict later language performance. Although age of implantation was found to be a significant factor for the RDLS receptive and expressive language scores, it was not a significant factor for the CELF scores or for the impact that early language measures had on later language performance.

\section{Acknowledgements}

The authors are grateful to three anonymous reviewers who provided valuable comments on an earlier version of the manuscript. This work was supported by NIH/NIDCD R01 DC000064 and the Psi Iota Xi National Organization.

\section{References}

Blamey PJ, Sarant JZ, Paatsch LE, Barry JG, Bow $\mathrm{CP}$, Wales RJ, Wright M, Psarros C, Rattigan $\mathrm{K}$, Tooher R: Relationships among speech perception, production, language, hearing loss, and age in children with impaired hearing. J Speech Lang Hear Res 2001;44:264285.

Connor CM, Craig HK, Raudenbush SW, Heavner K, Zwolan TA: The age at which young deaf children receive cochlear implants and their vocabulary and speech-production growth: is there an added value for early implantation? Ear Hear 2006;27:628644.

-Connor CM, Hieber S, Arts HA, Zwolan TA: Speech, vocabulary, and the education of children using cochlear implants: oral or total communication? J Speech Lang Hear Res 2000;43:1185-1204.

-Dawson PW, Busby PA, McKay CM, Clark GM: Short-term auditory memory in children using cochlear implants and its relevance to receptive language. J Speech Lang Hear Res 2002;45:789-801.
DesJardin JL, Eisenberg LS: Maternal contributions: supporting language development in young children with cochlear implants. Ear Hear 2007;28:456-469.

Dettman SJ, Pinder D, Briggs RJS, Dowell RC, Leigh JR: Communication development in children who receive the cochlear implant younger than 12 months: risks versus benefits. Ear Hear 2007;28:11S-18S.

Geers AE: Speech, language, and reading skills after early cochlear implantation. Arch Otolaryngol Head Neck Surg 2004;130:634-638.

-Geers AE, Brenner C, Davidson L: Factors associated with development of speech perception skills in children implanted by age five. Ear Hear 2003;24(suppl):24S-35S.

Geers AE, Nicholas JG, Sedey AL: Language skills of children with early cochlear implantation. Ear Hear 2003;24:46S-58S.

Johnson KC, DesJardin JL, Barker DH, Quittner AL, Winter ME: Assessing joint attention and symbolic play in children with cochlear implants and multiple disabilities: two case studies. Otol Neurotol 2008;29:246-250.

-Kirk KI, Miyamoto RT, Lento CL, Ying E, O’Neill T, Fears B: Effects of age at implantation in young children. Ann Otol Rhinol Laryngol Suppl 2002a;189:69-73.
- Kirk KI, Miyamoto RT, Ying EA, Perdew AE, Zuganelis $\mathrm{H}$ : Cochlear implantation in young children: effects of age at implantation and communication mode. Volta Rev 2002b;102:127-144.

Kirk KI, Sehgal ST, Hay-McCutcheon M: Comparison of children's familiarity with tokens on the PBK, LNT, and MLNT. Ann Otol Rhinol Laryngol Suppl 2000;185:63-64.

Miyamoto RT, Kirk KI, Svirsky M, Sehgal S: Longitudinal communication skill acquisition in pediatric cochlear implant recipients. Adv Otorhinolaryngol 2000;57:212-214.

Miyamoto RT, Myres WA, Pope ML, Carotta CC: Cochlear implants for deaf children. Laryngoscope 1986;96:990-996.

Moeller MP, McConkey AJ: Language Intervention with Preschool Deaf Children: A Cognitive/Linguistic Approach. New York, Thieme-Stratton, 1984.

Nicholas JG, Geers AE: Effects of early auditory experience on the spoken language of deaf children at 3 years of age. Ear Hear 2006;27: 286-298. 
Nippold MA, Hesketh LJ, Duthie JK, Mansfield TC: Conversational versus expository discourse: a study of syntactic development in children, adolescents, and adults. J Speech Lang Hear Res 2005;48:1048-1064.

-Pisoni DB: Cognitive factors and cochlear implants: some thoughts on perception, learning, and memory in speech perception. Ear Hear 2000;21:70-78.

Reynell JK, Huntley M: Reynell Developmental Language Scales: Second Revision. Windsor, NFER-NELSON, 1985.

- Rice ML, Redmond SM, Hoffman L: Mean length of utterance in children with specific language impairment and in younger control children shows concurrent validity and stable and parallel growth trajectories. J Speech Lang Hear Res 2006;49:793-808.

- Rice ML, Wexler K, Hershberger S: Tense over time: the longitudinal course of tense acquisition in children with specific language impairment. J Speech Lang Hear Res 1998;41: 1412-1431.

Robbins AM, Bollard PM, Green J: Language development in children implanted with the CLARION cochlear implant. Ann Otol Rhinol Laryngol Suppl 1999;177:113-118.
Robbins AM, Svirsky M, Kirk KI: Children with implants can speak, but can they communicate? Otolaryngol Head Neck Surg 1997;117: 155-160.

Scott CM: Producing complex sentences. Top Lang Disord 1988;8:44-62.

Scott CM, Stokes SL: Measures of syntax in school-age children and adolescents. Lang Speech Hear Serv Sch 1995;26:309-319.

Semel EM, Wiig EH, Secord W: Clinical Evaluation of Language Fundamentals, ed 3. San Antonio, The Psychological Corporation, 1996.

Semel EM, Wiig EH, Secord WA: Clinical Evaluation of Language Fundamentals, ed 4. San Antonio, The Psychological Corporation, 2003.

Spencer LJ, Barker BA, Tomblin JB: Exploring the language and literacy outcomes of pediatric cochlear implant users. Ear Hear 2003 24:236-247.

Spencer LJ, Gantz BJ, Knutson JF: Outcomes and achievement of students who grew up with access to cochlear implants. Laryngoscope 2004;114:1576-1581.

Stallings LM, Gao S, Svirsky MA: Assessing the language abilities of pediatric cochlear implant users across a broad range of ages and performance abilities. Volta Rev 2002;102: 215-235.
Streng AH, Kretschmer RR, Kretschmer LW: Language, Learning, and Deafness: Theory, Application, and Classroom Management. Orlando, Grune \& Stratton, Inc, 1978.

-Svirsky MA, Teoh SW, Neuburger H: Development of language and speech perception in congenitally, profoundly deaf children as a function of age at cochlear implantation. Audiol Neurootol 2004;9:224-233.

Tomblin JB, Barker BA, Hubbs S: Developmental constraints on language development in children with cochlear implants. Int J Audiol 2007;46:512-523.

Tomblin JB, Barker BA, Spencer LJ, Zhang X, Gantz BJ: The effect of age at cochlear implant initial stimulation on expressive language growth in infants and toddlers. J Speech Lang Hear Res 2005;48:853-867.

Tomblin JB, Spencer L, Flock S, Tyler R, Gantz B: A comparison of language achievement in children with cochlear implants and children using hearing aids. J Speech Lang Hear Res 1999;42:497-511.

Willstedt-Svensson U, Lofqvist A, Almqvist B, Sahlen B: Is age at implant the only factor that counts? The influence of working memory on lexical and grammatical development in children with cochlear implants. Int J Audiol 2004;43:506-515. 